\title{
Rise of Biobanking in the EU: Evidence from the Framework Programmes
}

\author{
L'UBiCA Kotorová SLuŠnÁ
}

Centre of Social and Psychological Sciences

Slovak Academy of Sciences

Šancová 56, 81105 Bratislava

SLOVAKIA

Miroslav BALOG

Centre of Social and Psychological Sciences

Slovak Academy of Sciences

Šancová 56, 81105 Bratislava

SLOVAKIA

\section{VLADIMÍR BALÁŽ}

Centre of Social and Psychological Sciences

Slovak Academy of Sciences

Šancová 56, 81105 Bratislava

SLOVAKIA

\section{EDITA NEMCOVÁ}

Centre of Social and Psychological Sciences

Slovak Academy of Sciences

Šancová 56, 81105 Bratislava

SLOVAKIA

RICHARD FILČÁK

Centre of Social and Psychological Sciences

Slovak Academy of Sciences

Šancová 56, 81105 Bratislava

SLOVAKIA

TOMÁŠ JECK

Centre of Social and Psychological Sciences

Slovak Academy of Sciences

Šancová 56, 81105 Bratislava

SLOVAKIA

MARTINA ANTOŠOVÁ

University Hospital Martin

Kollárova 2, 03601 Martin

SLOVAKIA 
Abstract: - The topic of biobanking has been anchoring in the world and Europe as well. The biobanking field today is characterised by heterogeneous entities that could be classified according to many different categories. This article aims to outline the process of the gradual embedding of the field of biobanking in the European Union (EU) from the point of view of the number of high-quality international research projects related to biobanking or biobanks as such. To identify these research projects, data from the European Commission's (EC's) database on research and innovation projects financed from Framework Programmes (FPs) of the European Union and the Horizon programme were used. It was found that the number of research and innovation projects in which biobanks played an important role more than doubled between 1994 and 2021. The highest increase in the number of biobank-related research and innovation projects occurred between $2002-2006$ and 2007 - 2013. Several leading countries, in terms of the number of biobank related research projects, emerged during the whole period. The main actors were all countries of western Europe, characterised mostly by above-average performance in indicators such as GDP per capita, Human Development Index (HDI) or Euro Health Consumer Index (EHCI).

Key-Words: - Biobank; Biobanking; Research and Development; Research projects; European Union; Framework Programmes

Received: April 13, 2021. Revised: September 27, 2021. Accepted: October 19, 2021. Published: November 1, 2021.

\section{Introduction}

Mean research and development (R\&D) costs of developing a new medicine (therapeutic agent) and bringing it to market has been estimated at approximately USD 1.3 billion (median costs at USD 985 million), with differences according to the area of treatment [1]. The cost of non-communicable diseases (cardiovascular diseases, cancers, chronic respiratory diseases, diabetes) is estimated to reach USD 30 trillion during 2010-2030 [2] which is equivalent to $35 \%$ of the 2020 world gross domestic product (GDP) (USD 84.7 trillion according to the World Bank data). In 2019, non-communicable diseases were responsible for $74 \%$ of all deaths [3]. These findings are just a few examples that support the need for $R \& D$ of new drugs and diagnostic procedures. For more effective $R \& D$, the creation of unique infrastructures is supported, the so-called biobanks. According to the Statutes of the Biobanks and Biomolecular Resources Research Infrastructures Consortium (BBMRI-ERIC) as a European Research Infrastructure Consortium, biobanks are defined as 'collections, repositories and distribution centres of all types of human biological samples, such as blood, tissues, cells or DNA and/or related data such as associated clinical and research data, as well as biomolecular resources, including model- and micro-organisms that might contribute to the understanding of the physiology and diseases of humans' [4].

Providers of biological samples are donors, i.e., individuals (patients or healthy individuals) who voluntarily choose to provide biological material for research purposes. Details regarding the process of donation and subsequent use of samples are approached differently by individual biobanks, depending on the legal conditions valid in the countries in which they operate. There is agreement on two basic, generally accepted conditions, namely the anonymity of donors and the voluntary nature of the provision of samples. The biobank may only collect samples to which the donors have given their consent. This requirement arises from the World Medical Association Declaration of Helsinki: Ethical Principles of Medical Research Involving Human Subjects, first adopted in 1964. However, due to applicability to current conditions, it has been revised several times, with the last revision in 2013 [5].

The key for the biobank is to obtain a sufficient number of samples with relevant data on medical history, lifestyle, behaviour and environment. At present, great emphasis is placed on ensuring that the samples are high-quality and the data is accurate, reliable and standardised.

The International Organization for Standardization (ISO) defines biobanking as a process of acquisitioning and storing, together with some or all of the activities related to collection, preparation, preservation, testing, analysing and distributing defined biological material as well as related information and data [6]. Biobanks that aspire to be at the top of the ladder need also to perform other forms of activity, such as the correlation of clinical and molecular data, the use of new techniques in the 
analysis of existing samples or the application of personalised medicine concepts [7].

Biobanking has become a research discipline [8]. Its activities overlap with many other prospective scientific disciplines, such as genomics, proteomics, biochemistry, bioinformatics, transcriptomics and others [9]. Biobanks are perceived as research infrastructures [10] or their critical parts [11]. In many cases these are truly large-scale infrastructure projects. The largest biobanks include Biobank Graz, Austria, with a collection of around 20 million human-derived samples [12], the Shanghai Zhangjiang Biobank, China, (a commercial biobank), with a storage capacity of 10 million samples (the third phase of this project should reach storage capacity of 50 million) [13] and the All of Us biobank in the USA, which aims to reach 1 million donors [14]. According to a Fortune Business Insights Report, the size of the global biobanking market in 2018 was at USD 25 billion (the size of the European biobanking market was USD 8.9 billion) with projections to reach USD 49.5 billion in 2026 [15].

We are currently witnessing rapid technological development in the field of biomedicine. For instance, biotechnological innovations or sequencing technologies create space for the development of disciplines such as personalised medicine, genomics and proteomics. Biobanks are a key element in this environment, as they provide inevitable inputs for these promising disciplines and represent important and necessary infrastructures for their further development.

Kinkorová [16] describes biobanking as a branch or pillar of personalised medicine. This connection is implemented in practice, e.g., within MyCode biobank, particularly the MyCode Community Health Initiative, established in 2012, as a research platform covering the biobank and clinical data in the electronic health records of biobank participants. As part of the initiative, the biobank is linked to electronic health records. In 2013, they went even further and decided to begin the process of returning clinically feasible results to patients. The original broad consent of donors was modified by the possibility of including a permit for the return of research results into the health documentation of donors [17].

The COVID-19 pandemic had a significant impact on health care, and also on the functioning of biobanks. Patients with COVID-19 have become a priority, and some biobanks have reoriented themselves to the research, collection and storage of samples for covidrelated research [18]. In addition to changes in research priorities, there have been changes in clinical trials, changes in health care delivery with fewer patients visiting specialists and a direct impact on biobank funding [9]. Also, the pandemic has brought many opportunities for biobanks, such as better cooperation between the public and private sectors or emphasising their role in the basic research or development of drugs and vaccines [19]. Greater importance has also begun to be attached to viral biobanks, which represent collections of viruses and derived products used in research. An example is The European Virus Archive (EVA) biobank that was created in 2008 as a virtual research infrastructure and was funded by the EC [20].

There is no doubt that the topic of biobanking is attracting greater attention from scientists, policymakers, businesses and the public in general. It is no longer a marginal field. In this paper, we aim to outline the process of gradual embedding of the field of biobanking in the EU from the point of view of the number of high-quality international research projects related to biobanking or biobanks as such. Several research articles note the rise of biobanking over the last two decades. However, they do not provide sufficient evidence for this statement, nor a more detailed insight into this development. This is the first paper that uses data for a long period, from 1994 to 2021 to identify certain time and geographical patterns in the development of biobanking within the EU. This article uses comprehensive methodology, focusing on various, commonly used, versions of the term biobank to identify biobank-related research projects. Resultant identification of leading countries that have emerged during the period analysed could be of interest for other researchers, biobank managers or policymakers. Evidence-based knowledge about the evolution of biobanking and its international context is important for future research and analytical reports. In the literature review section, we introduce the biobanking field from the theoretical point of view, providing an overview of the various types of biobanks and examples of a wide range of their impact defined in scientific literature. In the results chapter, using data from EU-funded research projects databases, the periods defined by the expansions in the number of research projects and main countries participating in biobanking research projects are identified.

\section{Literature Review}

According to Vaught, Henderson and Compton [21], the first biorepositories for storing biological samples, mainly for R\&D purposes, existed in various forms as early as 150 years ago. In the beginning, these were mainly small, university-based 
repositories for the purpose of their use in specific projects. According to the BBMRI, the forerunners of today's biobanks were paraffin-embedded tissue sample collections created at many pathological institutes across Europe. These began to systematically collect and store samples from at least the beginning of the nineteenth century [10].

Hewitt and Watson [22] state that the term 'biobank' first appeared in scientific literature in 1996. A targeted search (using the keyword 'biobank' in title or abstract of publication) in the Scopus or PubMed databases confirmed this. However, using a more extensive definition, meaning searching for keywords, such as 'tumour bank' or 'tissue bank', we are able to find a scientific article focused on biobanking as early as 1955 (an article titled 'The Tissue Bank and Military Medicine' published in The Journal of the American Medical Association). The term 'tumor bank' appeared in scientific literature two years later.

Since then, biobanking has undergone significant changes. Gradually, larger, more sophisticated and professionalised biorepositories evolved. These changes were happening in a decentralised manner [23] and thus, currently, various types of biobanks operate worldwide that together form highly heterogeneous field. Biobanks could be classified based on various characteristics.

Table 1. Overview of different types of biobanks based on various classifications found in scientific literature

Based on the sample size stored in the biobank [24]

- Large-scale biobanks that focus on long-term research projects

- Small-scale biobanks that focus on specific research projects and usually store up to several thousand samples

Based on the research focus [24]

- Population-based biobanks that target healthy individuals of a particular population or ethnic group

- Disease-oriented biobanks that focus on biological material from patients with certain diseases; samples often taken repeatedly and treatment progress monitored

- Case-control biobanks target similar individuals (at least in terms of age and gender) with the same diagnosis.

- Tissue banks collect and store a variety of tissue samples along with detailed information on the nature of the disease; they are obtained through methods such as invasive medical procedures and biopsies.
- Clinical trial-related biobanks collect samples and data for clinical trials to identify biomarkers associated with a particular disease.

- Other specific biobanks, such as those focused on cord blood and stem cells

Based on the required level of expertise and specialisation [25]

- Generalist biobanks that have a broad scope and a lower level of expertise

- Specialist biobanks that have a specialised focus and a higher level of expertise

Based on the main types of biomarkers they focus on [26]

- Biobanks that focus on biomarkers of susceptibility and identity target many healthy donors (population banks)

- Biobanks that focus on biomarkers of exposure (disease-oriented biobanks for epidemiology)

- Biobanks that focus on disease biomarkers through samples of tumours and their derivatives (general disease-oriented biobanks)

Based on user type [27]

- Mono-user biobanks store samples only for specific research and only for the duration of that research (mostly very small biobanks).

- Poly-user biobanks that store samples for research projects that are not predetermined, and collections of these biobanks might be used by several users trying to answer various research questions.

- Oligo-user biobanks that store samples for several research projects, mostly within one institution

Gee et al. [28] propose additional categories for the classification of biobanks. Among them are purpose, location, ownership, scale, nature of the content, financial sources (e.g. government department, academia, industry, non-profit organisations, patient organisations and charities) or access conditions (e.g. an exclusive approach in which third parties are excluded; controlled access in which access for third parties is possible on request and under certain conditions-the most common access; open access).

Malsagova et al. [29] list several types of biobanks. Some of them could be considered a result of the latest technology and research progress, such as:

- organoid biobanks that store organoids - miniorgans - can be grown from various types of stem cells;

- imaging biobanks that store images obtained with modern technologies, such as computed tomography, magnetic resonance and positron emission tomography; and

- digital biobanks. 
The current COVID-19 pandemic has also had an impact on biobanking. Kinkorová [16] mentions that due to the pandemic, a new phenomenon has emerged, which is the creation of Covid biobanks.

Biobanks operate in an environment with very particular conditions. It is not a classic market, where prices are the result of competition or market forces. Human samples must not be sold for profit according to applicable regulations. On the other hand, the biobank needs considerable funds for its activities, which must be obtained from external sources. This means that biobank must constantly prove its necessity and importance to the providers of funds. Underestimating its benefits decreases biobank's ability to raise funds [30]. The biobank environment is created by many different subjects. According to Ciaburri et al. [31], the following groups are among the actors involved in the functioning of the biobank: donors and patients, researchers, private or public sector partners, public institutions (especially legislation, financing, regulations), employees, financial supporters, consortia, networks or partnerships.

As the biobank operates in a very particular market involving many different actors with different interests, measuring its benefits or impacts is an extremely complex task. The scientific literature mentions a wide range of impacts in different areas. Chalmers et al. [32] describe the biobank as a basic tool for translating biomedical research into practice. According to Bioy [25], the economic valorisation of biobanks is primarily a question of the valorisation of research. Samples stored in biobanks represent inputs for research activities. These inputs can influence the quality of research, the emergence of innovations, discoveries, the diagnosis and treatment of diseases. Researchers publish their results in scientific studies; therefore, these are considered as outputs of the biobank. Publishing results is beneficial for the individual researcher or research team, research institution and other researchers who can build their further research on these results. However, the outputs of the biobanks are not only individual research results, which represent the results of research studies defined within their objectives, but also random discoveries that are not defined in their objectives [33]. Report of the European Commission's Joint Research Center [34] provides an approximate quantification of the outputs of biobanks in the field of scientific publications and scientific collaborations. The study is based on a survey of a sample of 126 European research biobanks. Of the addressed biobanks, almost half of them (46\%) stated that providing samples to researchers resulted in $1-$
10 research publications and $38 \%$ of biobanks stated more than 10 publications (28\% stated more than $100,10 \%$ stated $11-100$ ). Only $16 \%$ of those surveyed stated no scientific publications. Nearly half $(45 \%)$ of biobanks reported more than 10 research collaborations, $40 \%$ of biobanks reported between 2 to 20 collaborations whereas only $13 \%$ reported no research collaboration [34]. Biobank is essential for personalised medicine, the discovery of effective biomarkers and evidence-based interventions to improve population health. Biobank networks are essential for health research as well as the provision of health services [35]. Samples are often taken as part of patient care. If those samples are also used for research, it may benefit the patient and many others. A new drug or therapeutic method can have the effect of shortening or streamlining treatment, reducing the cost of treatment and thus the quality and length of life of patients. Biobanks, are able to support the whole process of drug discovery and drug development [36]. With the possibility of using samples for commercial research, the biobank also has an impact on business development, job creation, the inflow of foreign investment, or the solution of the brain drain problem. Nevertheless, policymakers seem to underestimate the potential value of biobanks for public health [37].

\section{Methodology}

Gradual embedding of biobanking within the EU was analysed from the point of view of the number of high-quality international research projects related to biobanking or biobanks as such. To identify these research projects, data from the European Commission's database on Community Research and Development Information Service (CORDIS) projects financed from Framework Programmes (FPs) of the EU and the Horizon programme that are considered high-quality projects with trans-European coverage, were used. Databases were downloaded in May 2021. The identification of projects related to biobanking was carried out through a search in the names and objectives (short descriptions) of projects. First, the search was performed for the term 'biobank.' Second, the search was performed again, but this time it was done using various alternative versions of the term biobank. The reason is that terms other than biobank are often used in the field of biobanking. Examples are genetic bank, bank of tissues, specimen bank and others. Based on this knowledge, the search was conducted using the keywords: 'repository' and 'bank' and only the projects containing any of the following terms were chosen from the results: 'sample' or 'specimen' or 
'tissue' or 'tumour' or 'tumor' or 'DNA' or 'genetic.' After this selection, the results were checked manually and projects unrelated to human biobanks were excluded (e.g. projects related to agriculture, plants, software or finance). These final results were then integrated with the results for the term 'biobank' (duplicates removed) to get a broadly defined category.

Identification of main countries involved in these projects was carried out by filtration of individual countries in the column 'Participant country' and then in the column 'Coordinator country' of the databases for each FP and Horizon programme. Next, basic descriptive statistics regarding the total costs of all the identified projects for each period (average, minimum, maximum, median) were calculated. Data about real GDP per capita were extracted from the Eurostat database (Chain linked volumes 2010). As a composite index capturing life expectancy at birth, years of schooling and GNI per capita (PPP dol.), the HDI was extracted from United Nations Industrial Development Organization (UNIDO) database. Data for the period 2017 - 2019 were used and average for this period was calculated for each indicator. Data about the total population were extracted from Eurostat (on January 2020). Also, the EHCI was presented, specifically the rank for each country. EHCI assesses national healthcare systems' performance in 35 countries, comprising various areas such as access to care, treatment outcomes, patient rights, range and reach of services, prevention and use of pharmaceuticals. Data were extracted from the last available report for 2018 .

\section{Results}

\subsection{Evolution in the field of biobanking based on data about EU-financed research and innovation projects}

The EU has provided vast financial resources for international research and innovation projects from its FPs or Horizon programme. Among supported projects were also $R \& D$ projects directly focused or closely related to biobanking.

For the period analysed (from 1994 till April 2021), we identified 165 research projects where the term biobank was mentioned. This number is not significant considering the number of all projects financed from these programmes during this period. However, the growth rates of new projects in successive periods are substantial. As results from our search shows (Fig. 1), there is no reference of biobank or biobanking among the projects financed from the 4th Framework programme (1994 - 1998).
Few projects related to biobanks were financed from the 5th Framework Programme during the period 1998 - 2002. As shown in Fig. 1, the term biobank has been more frequently used in projects financed from FP 6 in 2002 - 2006. The highest growth rate was achieved in the subsequent period, $2007-2013$. The number of research projects jumped from 15 to 68 in FP 7. During the next period, 2014-2020, there is an increase in the number of biobank-related research projects; however, this increase is smaller than in previous periods.

Fig. 1 The number of the scientific research projects related to biobanks financed from the EU FPs and Horizon 2020

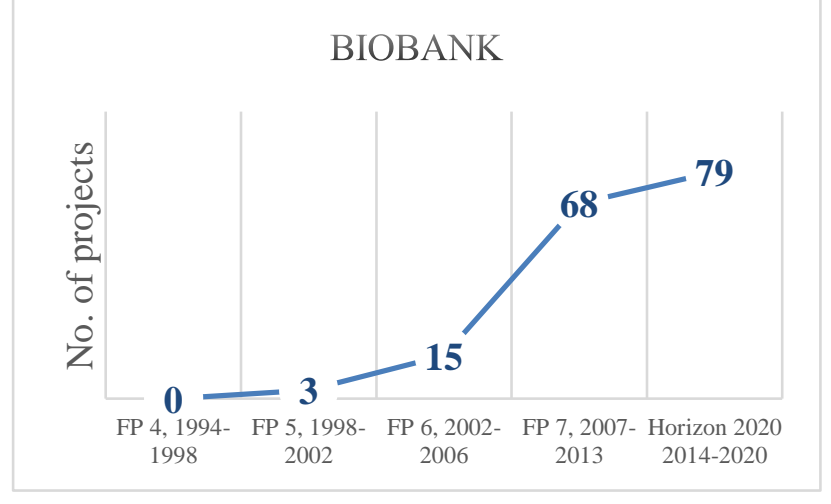

Results of extended search (using more versions of the term biobank) were slightly different, however, patterns were very similar. Although the term biobank was not used when describing projects financed from FP 4, many research projects have already focused on creating a repository of biological material or gene mapping. One example is the European gene vector database and repository project. The number of projects related to biobanking increased slightly between FP4 (1994 - 98) and FP5 (1998 - 02) periods. Their growth rate accelerated during the next period and the highest growth rate of the number of biobank-related research projects was achieved during 2007 - 2013. Horizon 2020 offered significant funding for biobanking initiatives as well. However, there seems to be a peak achieved during the previous period.

Fig. 2 The number of the scientific research projects related to biobanks (extended definition) financed from the EU FPs and Horizon 2020 


\section{BIOBANK EXTENDED DEFINITION}

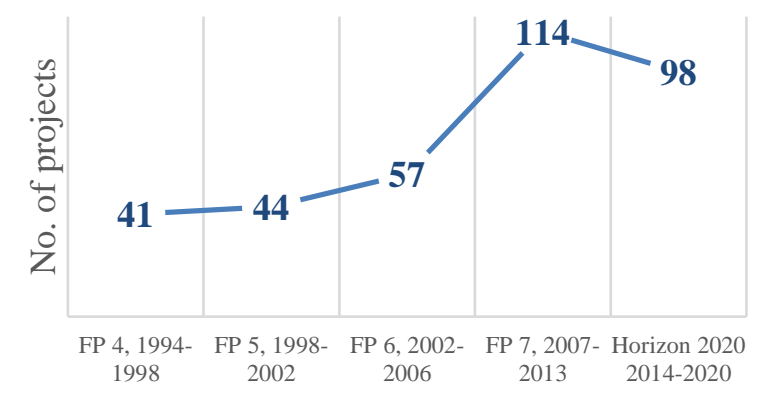

The identification of research projects mentioned earlier (Fig. 2) enabled us to outline the financial perspective of this research area and identify countries with the highest participation.

Among the identified projects in individual periods were smaller projects with total costs of several tens of thousands of euros and projects with a total cost exceeding EUR 50 million. The difference between the average costs of EUR 5.4 million and the median costs of EUR 2.4 million suggests that there was a higher number of projects with lower costs. The average and median costs of a project have been increasing in the subsequent FPs. The Horizon programme represented a slight decrease in the average and median cost of a project. For the whole period, the EU and subjects participating in projects (since the total costs of some projects exceeded EC maximum contribution) invested significant financial resources into biobank-related research and development.

Table 2 Basic descriptive statistics regarding costs of identified projects

\begin{tabular}{|c|c|c|c|c|c|}
\hline & FP 4 & FP 5 & FP 6 & FP 7 & $\begin{array}{c}\text { Horizon } \\
2020\end{array}$ \\
in $€$ & in $€$ & in $€$ & in $€$ & in \\
\hline $\begin{array}{c}\sum \\
\text { total } \\
\text { cost }\end{array}$ & $\begin{array}{c}14199 \\
29\end{array}$ & $\begin{array}{c}728124 \\
86\end{array}$ & $\begin{array}{c}249396 \\
516\end{array}$ & $\begin{array}{c}779617 \\
723\end{array}$ & $\begin{array}{c}573869 \\
161\end{array}$ \\
\hline MAX & $\begin{array}{c}690 \\
000\end{array}$ & $\begin{array}{c}10545 \\
416\end{array}$ & $\begin{array}{c}23400 \\
000\end{array}$ & $\begin{array}{c}54128 \\
037\end{array}$ & $\begin{array}{c}40922 \\
059\end{array}$ \\
\hline MIN & 129 & 147500 & 19950 & 75000 & 71429 \\
\hline AVG & $\begin{array}{c}354 \\
982\end{array}$ & $\begin{array}{c}1733 \\
631\end{array}$ & $\begin{array}{c}5542 \\
145\end{array}$ & $\begin{array}{c}6899 \\
272\end{array}$ & $\begin{array}{c}5855 \\
808\end{array}$ \\
\hline MED & 300 & 1366 & 2773 & 3687 & $\begin{array}{c}3 \\
434\end{array}$ \\
& 000 & 507 & 908 & 429001 \\
\hline
\end{tabular}

Continued funding suggests that research and development needs are still not saturated and continuous upgrading is still necessary.

\subsection{Identification of leading countries within the $\mathbf{E U}$}

During the individual periods under review, the composition of leaders involved in research projects related to biobanks did not change much. Fig. 3 shows the map of the European countries, where the size of a blue dot represents the number of projects in which the country participated during the whole period analysed (1994 - 2021). We focused only on EU countries (although countries outside the Europe, such as the USA, Israel, Australia and Canada participated in these projects as well) plus Switzerland, Norway, the UK and Iceland. We found out that the leaders in research projects related to biobanking were countries of western Europe. If they were EU members, they were either the founding members of the EU or members who joined the EU in its early years.

Fig. 3 Map of European countries based on their participation in research projects for the whole period

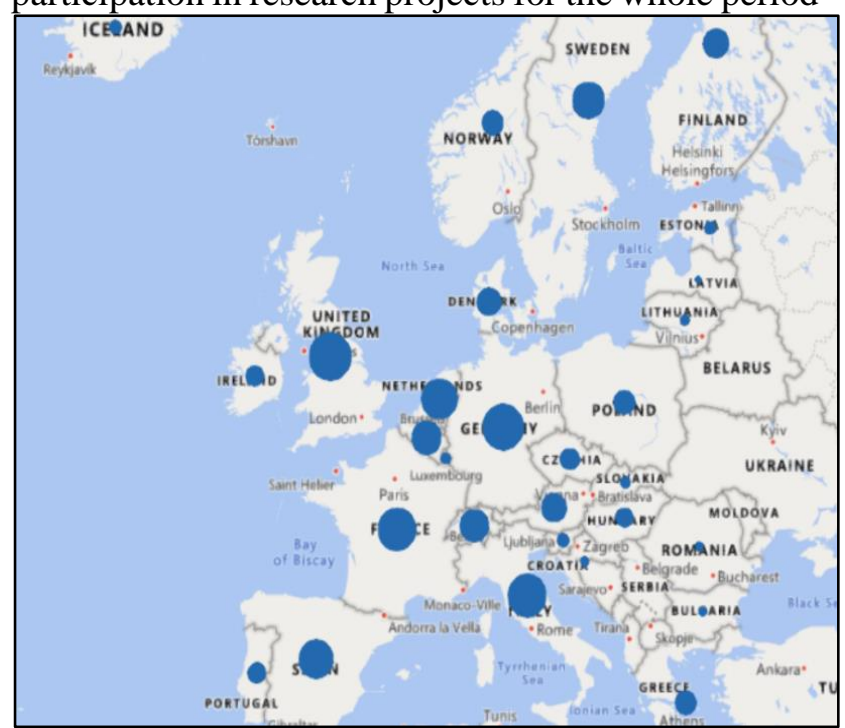

For the countries on the map, certain additional indicators were identified. Table 3 displays leading European countries involved in biobanking projects sorted according to the number of research projects where they declared participation for the whole period analysed. The second column displays the number of projects where the country operated as a coordinator (the coordinator is usually the project's initiator). Countries with the highest participation in projects were also most active as coordinators or initiators of projects (country could have been either coordinator or participant or both; in several cases, the database did not contain the data about participant countries, only the data about coordinator countries).

Table 3 Leading countries according to their participation in biobanking projects 


\begin{tabular}{|c|c|c|c|c|c|}
\hline & $\begin{array}{c}\text { Participant } \\
\text { country }\end{array}$ & $\begin{array}{c}\text { Population } \\
\text { millions }\end{array}$ & $\begin{array}{c}\text { Participant } \\
\text { country } \\
\\
\text { No. of } \\
\text { projects } \\
\text { per } \\
100000 \\
\text { pop. }\end{array}$ & $\begin{array}{c}\text { Coordinator } \\
\text { country } \\
\text { No. of } \\
\text { projects }\end{array}$ & $\begin{array}{c}\text { Average } \\
\text { total } \\
\text { costs per } \\
\text { project } \\
\\
\text { million } \\
€\end{array}$ \\
\hline $\begin{array}{c}\text { United } \\
\text { Kingdom } \\
\end{array}$ & 167 & 67 & 0,25 & 51 & 7,8 \\
\hline Germany & 156 & 83,2 & 0,19 & 41 & 8,4 \\
\hline Italy & 136 & 59,6 & 0,23 & 36 & 8,1 \\
\hline France & 136 & 67,3 & 0,20 & 35 & 8,7 \\
\hline Netherlands & 121 & 17,4 & 0,70 & 25 & 8,3 \\
\hline Spain & 109 & 47,3 & 0,23 & 21 & 8,2 \\
\hline Sweden & 99 & 10,3 & 0,96 & 22 & 9,5 \\
\hline Belgium & 85 & 11,5 & 0,74 & 16 & 10,7 \\
\hline Switzerland & 79 & 8,6 & 0,92 & 4 & 11,2 \\
\hline Finland & 63 & 5,5 & 1,15 & 5 & 11,5 \\
\hline Austria & 61 & 8,9 & 0,69 & 5 & 10,1 \\
\hline Denmark & 59 & 5,8 & 1,02 & 14 & 11,6 \\
\hline Norway & 46 & 5,4 & 0,85 & 12 & 9,3 \\
\hline Iceland & 14 & 0,4 & 3,5 & 1 & 11,1 \\
\hline Luxembourg & 11 & 0,6 & 1.83 & 0 & 17,6 \\
\hline
\end{tabular}

As seen in Table 3, leaders in biobanking research projects were mostly involved in large projects with higher-than-average project costs.

A positive correlation was found between the size of the population and the number of projects in which the country participated or was the project coordinator (see Fig 4 in Appendix).

Most active countries in terms of their participation, such as Great Britain, Germany, Italy, France, Netherlands and Spain, participated in more than 100 research projects related to biobanks during the period $1994-2021$. The second group comprised of Nordic countries of Sweden, Finland, Norway and Denmark, together with Belgium, Switzerland and Austria. These countries were also performing very well considering the size of their population. In the number of project participation per 100,000 people, at the top of the rankings were Iceland, Luxembourg and Finland.

Countries in Table 3 were evaluated according to their performance in indicators GDP per capita, HDI and the EHCI. It was found that almost all of the leading countries are characterised with aboveaverage performance in an indicator focusing on economic activity (GDP per cap.) and also an indicator that is considered as a proxy for measuring the quality of life (HDI) (Fig.5). The exceptions are Spain and Italy. Looking at their participation in research projects, one can notice high numbers in absolute terms, but not exceptional results in involvement in research projects in per capita terms.

Fig. 5 Comparison of performance of leading countries in biobanking projects with EU average in GDP per capita and HDI

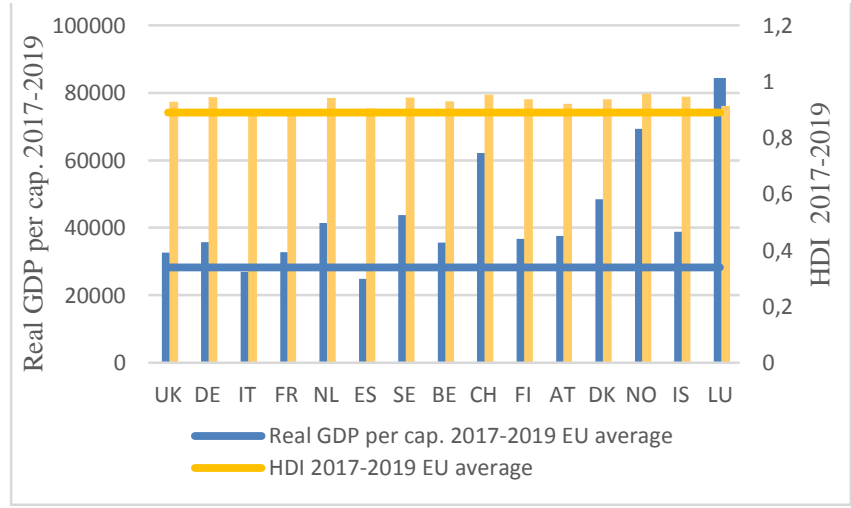

All of the identified leading countries are in the top 20 regarding their rank in the EHCI indicator $(66 \%$ of them are in the top 10). None of them is characterised by the poor performance of the health care systems.

Fig. 6 Comparison of rankings in EHCI, leading countries $\mathrm{v}$ other EU countries

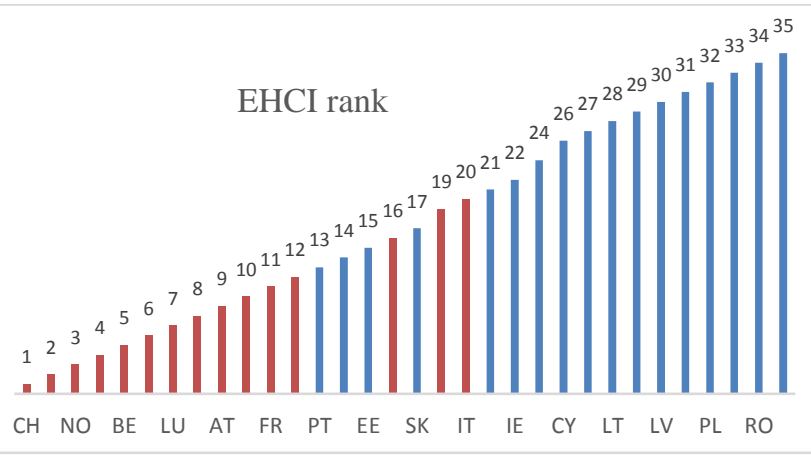

Note: leading countries are visualised in red colour

According to the BBMRI directory, many identified leading countries are characterised by a high number of biobanks; however, a significant correlation between research and development biobanking projects and the number of biobanks in a country was not found. At the top of the ladder with the highest number of biobanks is the United Kingdom with 143 biobanks. Then it is Sweden (116), Netherlands (110), France (95), Italy and Germany (50) [38].

Participation of countries from eastern Europe has been generally less intensive. To a large extent, this is due to their later accession to the EU, although some of them participated in EC financed research and development biobanking projects before they became EU members. Poland and the Czech republic 
were performing the best within this group of countries.

No significant correlation was identified between the rate of participation in biobanking projects and indicators evaluating performance in economic, social or healthcare areas. However, the aboveaverage results of the countries most involved in these projects suggest that biobanking is the domain of advanced countries and biobank related research and development might represent a tiny part of their success stories.

\section{Discussion}

Enormous progress in biobanking in the last two decades has been reported in many studies $[16,39,40]$. Several studies focused on specific aspects of this progress. For example, an increase in the number of hospital tumour biobanks [41] and the number of cohort biobanks in the past 10 years [42], also progress in collecting and storing samples [23], growth in the demand for quality, especially in the context of sample complexity [43], and an increase in the number of publications from 1996 to 2019 [23].

Data on the use of samples for oncology research reported in scientific studies were used to show increase in the demand for samples over the last two decades. An almost four-fold increase in cohort sizes between 1998 and 2008 was identified.[44]

Our study supports these findings and complements them with evidence about progress in biobanking in the context of R\&D. We have found that the number of research and innovation projects in which biobanks played an important role more than doubled between 1994 and 2021. The highest increase in the number of biobank- related research and innovation projects occurred between 2002 and 2006, and 2007 and 2013.

This is in line with evidence about the increase of biobanks. Henderson et al. [45] reported that $59 \%$ of biobanks were founded after 2000, which was based on a national survey of biobanks in the USA in 2012, in which 456 respondents (biobank representatives) participated. Only $17 \%$ of biobanks stated that their date of establishment was before 1990. The results for Europe (survey of a sample of 126 biobank representatives) show the same percentage of biobanks operating before 1990 and increasing percentages in the following periods [34]. A survey conducted in 2014 on those attending the International Society for Biological and Environmental Repositories (ISBER) symposium showed that most biobanks had been established between 2004 and 2009 [38]. A newer survey conducted at the end of 2017 on a sample of 276 biobanks showed that more than $66 \%$ of them had been established after 2007 [46].

Our methodology is unique as a comprehensive procedure of the search process. We have not focused only on the term biobank [such as, e.g., 23, 42, 47], but we built on findings identified during the national survey of biobanks in the USA, where different terminology was recognised as a major problem in identifying biobanks. [48].

We are aware that our methodology might still result in the omission of some projects related to biobanking that do not use the terms used in our methodology in their descriptions. Kinkorova, Topolčan [49] used different methodology, they identified biobank related projects financed from Horizon 2020 based on biobank involvement in the projects. Comparison of the results of their search with our search results shows that most of the projects identified by them also appear in our results. The geographical context of biobanking was introduced by the study of $\mathrm{Wu}$ et al. [42]. The analysis of publications in the Web of Science Core Collection database from 2009 to 2018 identified that the highest number of publications were from England. The USA and China were second and third and several EU countries followed, namely the Netherlands, Denmark, Sweden, Germany and Scotland. The study also revealed strong collaboration between researchers [42].

Meijer et al. [50] performed a social network analysis focusing on BBMRI members participating in biobank-related projects financed from FP5 and FP6. They identified Great Britain, Germany, Italy, France and the Netherlands as leading countries in terms of the number of research projects. They identified substantial increases in the number of participants during these two periods and increases in the complexity of the network.

The top position of the UK, identified by the abovementioned studies, but also by our results might be in our opinion related to the existence and success of the UK biobank, which since March 2012 has opened access to its databases for researchers from all over the world. It states on its website that it has recorded more than 19,000 registrations from around the world and provided data for around 1,465 scientific publications. Its success also stems from the fact that within the UK biobank they are able to link samples and data in the biobank to National Health Service Records [51].

Findings concerning the growth of biobanking in the last two decades are also confirmed by the development of its wider ecosystem. The development of biobanking was supported by international or regional organisations, initiatives as 
well as many guidelines, documents and recommendations that resulted from their work.

The ISBER was established in 2000. The annual report for 2020 shows that memberships numbers (large, medium, small organisations and individuals) increased in 2020 compared to 2004 by more than three times (from 172 to 584) [52]. Different stakeholders in the field of biobanking meet every year at a conference organised by ISBER to exchange the latest developments.

Among the key players in biobanking there is the BBMRI-ERIC, Europe's largest biobanking infrastructure. It aims to improve biomedical research by bringing together biobanking actors, namely researchers, biobankers, industry and patients. They provide management services, legal, legislative and social support and a variety of online tools and software solutions. It is an infrastructure project of strategic importance to the EU (founded in 2013). Currently, this brings together organisations from 20 countries and one international organization [53]. Figure 7 that is set out in Appendix shows on the timeline, examples of other regional or global organisations according to the date of their creation.

There have also been developments in legislation, regulations and guidelines, although many scientific studies still point to the need for greater harmonisation.

\section{Conclusion}

Although certain forms of biobanks existed more than 100 years ago, biobanks in the form they operate today and the field of biobanking in its current form are relatively new. The number of biobanks and their average size is growing and biobanks are becoming increasingly interconnected [10]. The biobanking field today is characterised by heterogeneous entities that could be classified according to many different categories. Various impacts on different aspects of the socio-economic environment have already been identified. However, more research is still needed in this area $[30,54,55]$.

As stated before, significant progress in biobanking has occurred during the last two decades. Many international institutions supporting biobanking have emerged, the number of new biobanks has increased, and more attention has been paid to this field. Currently, biobanking is characterised by a large number of global or regional organisations focused on various aspects of biobanking. Organisations supporting the biobanking field are nowadays localised in almost every region of the world, not excluding Africa or Asia.

The interdisciplinarity, large amounts of samples and data, together with the state-of-the-art technologies used by biobanks, create the need for different types of specialists that are important for biobanks, with knowledge in biology, medicine, bioinformatics, epidemiology, biochemistry, as well as engineering or economics and finance [56].

We have discussed the evolution of biobanking from multiple perspectives and compared our results with evidence from other research studies. We were able to identify several leaders in this area. Leading countries were usually involved in bigger projects with higher costs. All belong to western Europe. Almost all leading countries (in absolute terms and considering the size of their population) are characterised with above-average performance in indicators such as GDP per capita, HDI or EHCI, suggesting that biobanking is the domain of advanced countries that in general spend more resources on R\&D.

We have found that the number of research and innovation projects in which biobanks played an important role more than doubled between 1994 and 2021. Recent growth of biobanking and the development in closely related fields for which biobanks provide key inputs suggests a high potential for further progress of this young, but already wellestablished and thriving field.

\section{References:}

[1] Wouters O.J, McKee M, Luyten J, Estimated Research and Development Investment Needed to Bring a New Medicine to Market, 20092018, JAMA, Vol. 9, No. 323, 2020, pp. 844853. doi:10.1001/jama.2020.1166

[2] Bloom, D.E. et al, The Global Economic Burden of Noncommunicable Diseases. A report by the World Economic Forum and the Harvard School of Public Health, 2011, Geneva. https://www3.weforum.org/docs/WEF_Harvard _HE_GlobalEconomicBurdenNonCommunicab leDiseases_2011.pdf

[3] GBD 2019 Diseases and Injuries Collaborators, Global burden of 369 diseases and injuries in 204 countries and territories. 1990-2019: a systematic analysis for the Global Burden of Disease Study 2019, Lancet, 2020, doi: 10.1016/S0140-6736(20)30925-9

[4] Official Journal of the European Union, Commission implementing decision of 22 November 2013 on setting up the Biobanks and Biomolecular Resources Research Infrastructure Consortium (BBMRI-ERIC) as a European Research Infrastructure Consortium. Statuses, Chapter I, Article 1, 2013, https://eur-lex.europa.eu/legal- 
content/EN/TXT/HTML/?uri=CELEX:32013D

0701\&from=EN\#d1e116-64-1. Accessed

18.10 .2021

[5] The World Medical Association, Declaration of Helsinki- Ethical Principles for Medical

Research Inolving Human Subjects, https://www.wma.net/policies-post/wmadeclaration-of-helsinki-ethical-principles-formedical-research-involving-human-subjects/. Accessed 20.10.2021

[6] International Organization for Standardization, ISO 20387:2018 Biotechnology - Biobanking General requirements for biobanking, 2018, https://www.iso.org/standard/67888.html Accessed 17.9.2021

[7] Paskal W. et al, Aspects of Modern Biobank Activity - Comprehensive Review. Pathol Oncol Res, Vol. 24 , No. 4, 2018, pp. 771-785, doi: 10.1007/s12253-018-0418-4.

[8] Watson P.H. et al, Evolutionary concepts in biobanking - the BC BioLibrary. Journal of Translational Medicine, Vol.7, No.95, 2009, doi:10.1186/1479-5876-7-95

[9] Byrne J.A. et al, Building Research Support Capacity across Human Health Biobanks during the COVID-19 Pandemic, Biomarker Insights, 2021, doi: 10.1177/11772719211024100.

[10] BBMRI, Biobanks and the public, Governing Biomedical Research Resources in Europe, A report from the BBMRI project, 2013, https://www.bbmri-eric.eu/wpcontent/uploads/2016/08/BBMRI-Biobanksand-the-Public.pdf. Accessed 1.9.2021.

[11] Matzke L.A. et al, Finding the Value in Biobanks: Enhancing the CTRNet Locator, Biopreservation and Biobanking, online ahead of print, 2021, doi.org/10.1089/bio.2021.0043

[12] MedUni Graz, International Biobanking Education. https://www.medunigraz.at/internationalbiobanking-education Accessed 17.10.2021

[13] Shanghai Zhangijang Biobank. About us. http://www.shbiobank.com/about.html Accessed 18.10.2021

[14] All of Us biobank. Mayo Clinic announces biobank will store samples. https://allofus.nih.gov/news-events-andmedia/news/mayo-clinic-announces-biobankwill-store-samples-nih-all-us-precision Accessed 18.10.2021

[15] Fortune Business Insights, Biobanking Market Size, Share and Industry Analysis, Market research report. https://www.fortunebusinessinsights.com/bioba nking-market-102073. Accessed 17.7.2021

[16] Kinkorová J, Education for future biobankers The state-of-the-art and outlook, EPMA J, Vol. 15, No. 25, 2021, doi: 10.1007/s13167-02100234-5

[17] Faucet W.A, How Geisinger made the case for an institutional duty to return genomic results to biobank participants, Applied \&

Translational Genomics, Vol. 8, pp. 33-35, 2016, doi: 10.1016/j.atg.2016.01.003

[18] Henderson M.K, The Responses of Biobanks to COVID-19, Biopreserv Biobank, Vol. 18, No. 6, pp. 483-491, 2020, doi: 10.1089/bio.2020.29074.

[19] Simeon-Dubach D, Henderson M.K, Opportunities and Risks for Research Biobanks in the COVID-19 Era and Beyond, Biopreserv Biobank, Vol. 18, No. 6, pp. 503-510, 2020, doi: 10.1089/bio.2020.0079.

[20] Coutard B, The Importance of Biobanking for Response to Pandemics Caused by Emerging Viruses: The European Virus Archive As an Observatory of the Global Response to the Zika Virus and COVID-19 Crisis, Biopreserv Biobank, Vol. 18, No. 6, pp. 561-569, 2020, doi: 10.1089/bio.2020.0119.

[21] Vaught J.B., Henderson M.K. and Compton C.C., Biospecimens and biorepositories: from afterthought to science, Cancer Epidemiol Biomarkers Prev, Vol. 21, No. 2, pp. 253-255, 2012, doi: 10.1158/1055-9965.EPI-11-1179

[22] Hewitt R., Wattson,P., Defining biobank, Biopreservation and Biobanking, Vol. 11, No. 5, pp. 309-315, 2013, doi.org/10.1089/bio.2013.0042

[23] Coppola L. et al, Biobanking in health care: evolution and future directions, Journal of Translational Medicine, Vol. 17, No. 172, 2019, doi: 10.1186/s12967-019-1922-3.

[24] European Commission, Biobanks for Europe. A challenge for governance. Report of the Expert Group on Dealing with Ethical and Regulatory Challenges of International Biobank Research, 2012, doi:10.2777/68942

[25] Bioy X, Public Regulation of Tumor Banks, Establishment, Heritage Status, Development and Sharing of Human Biological Samples. 1st ed. Toulouse: Springer; 2018.

[26] Riegman P.H.J. et al, Biobanking for better healthcare, Molecular Oncology, 2008, No. 20008, pp. 213-222.

[27] Watson P.H., et al, A framework for biobank sustainability, Biopreservation and Biobanking, 
2014, Vol. 12, No.1, pp. 60-68, doi: 10.1089/bio.2013.0064

[28] Gee S. et al, Biobank Finances: A SocioEconomic Analysis and Review,

Biopreservation and Biobanking, Vol.13, No.6, 2015, doi: 10.1089/bio.2015.0030

[29] Malsagova K. et al, Biobanks: A Platform for Scientific and Biomedical Research, Diagnostics, Vol.10, No.7, 2020, doi:10.3390/diagnostics10070485(2020).

[30] Rush A, et al, Improving Academic Biobank Value and Sustainability Through an Outputs Focus, Value in Health, Vol.23, No.10, 2020, doi: 10.1016/j.jval.2020.05.010.

[31] Ciaburri M. et al, Business Planning in Biobanking: How to implement a tool for sustainability, Biopreservation and Biobanking, Vol.15, No.1, pp. 46-56, 2017, doi:10.1089/bio.2016.0045

[32] Chalmers D. et al, Has the biobank bubble burst? Withstanding the challenges for sustainable biobanking in the digital era, BMC Medical Ethics, 2016, pp. 17:39.

[33] Bemmels H.R., Wolf S.M. and Ness B.V., Mapping the inputs, analyses, and outputs of biobank research systems to identify sources of incidental findings and individual research results for potential return to participants, Genetics in Medicine, Vol.14, pp. 385-392, 2012, doi:10.1038/gim.2011.69

[34] Zika E. et al., Biobanks in Europe: Prospects for Harmonisation and Networking, JRC Working Papers JRC57831, Seville: Joint Research Centre; 2010.

[35] Yuillle M., Brave New World. Commentary, Biopreservation and Biobanking, Vol.13, No. 6, 2015, doi:10.1089/bio.2015.29040.my

[36] Asslaber M, Zatloukal K, Biobanks: transnational, European and global networks, Brief Funct Genomic Proteomic, Vol. 6, No. 3, 2007, pp. 193-201.

[37] Schulte In Den Baumen T, Paci D and Ibarreta Ruiz D., Data Protection and Sample Management in Biobanking - A legal dichotomy, Genomics, Society and Policy, Vol. 6, No. 1, pp. 34-47, 2010

[38] BBMRI-ERIC. Directory. https://www.bbmrieric.eu/directory/ Accessed 20.10.2021

[39] Simeon-Dubach D., Henderson M. K., Sustainability in Biobanking, Biopreservation and Biobanking, Vol. 12, No.5, 2014, doi: 10.1089/bio.2014.1251

[40] Barnes R.O, Watson P.H, Precision medicine: Driving the evolution of biobanking quality,
Healthc Manage Forum, Vol. 33, No.3, 2020, https://doi.org/10.1177/0840470419898874

[41] Hofman V. et. al, Measuring the contribution of tumor biobanks to research in oncology: surrogate indicators and bibliographic output, Biopreservation and Biobanking, Vol. 11, No.4, 2013, doi: 10.1089/bio.2013.0015.

[42] Wu D. et al, Ten Years of the Cohort Biobank: Bibliometric Outcomes, Biopreservation and Biobanking, Vol. 19, No.4, 2021, doi: 10.1089/bio.2020.0096.

[43] Hartman V, Matzke L, Watson P.H, Biospecimen Complexity and the Evolution of Biobanks, Biopreservation and Biobanking, Vol.17, No.3, 2019, doi: 10.1089/bio.2018.0120

[44] Hughes S.E, Barnes R.O, Watson P.H, Biospecimen Use in Cancer Research Over Two Decades, Biopreservation and Biobanking, Vol. 8, No. 2, 2010, doi: 10.1089/bio.2010.0005

[45] Henderson G.E, et al, Characterizing biobank organizations in the US: results from a national survey, Genome Medicine, Vol. 5, No.1, 2013, doi: 10.1186/gm407

[46] Henderson M.K, Goldring K, Simeon-Dubach $\mathrm{D}$, Advancing Professionalization of Biobank Business Operations: A Worldwide Survey, Biopreserv Biobank, Vol.17, No.1, 2020, doi: 10.1089/bio.2018.0079.

[47] Doucet M. et al, Biobank sustainability: current status and future prospects, Journal of Biorepository Science for Applied Medicine, Vol. 5, pp.1-7, 2017, doi: 10.2147/BSAM.S100899

[48] Boyer G.J. et al., Biobanks in the United States: How to Identify an Undefined and Rapidly Evolving Population, Biopreservation and Biobanking, Vol.10, No.6, 2012, doi:10.1089/bio.2012.0034

[49] Kinkorová J, Topolčan O, Biobanks in Horizon 2020: sustainability and attractive perspectives, EPMA J, Vol. 9, No. 4, 2018, doi 10.1007/s13167-018-0153-7

[50] Meijer I. et al, BBMRI: an evaluation strategy for socio-economic impact assessment.

Technopolis Group, 2010, http://www.technopolisgroup.com/resources/downloads/life_sciences/1 093_BBMRIfi... .Accessed 17.5.2021

[51] UK biobank. Our impact. https://www.ukbiobank.ac.uk/learn-moreabout-uk-biobank/our-impact Accessed 18.10.2021 
[52] ISBER. Anual report 2020. https://cdn.ymaws.com/www.isber.org/resource /resmgr/isber_2020/annualreport/isberannualre port2020_final.pdf Accessed 18.10.2021

[53] BBMRI-ERIC. https://www.bbmrieric.eu/national-nodes/ Accessed 18.10.2021

[54] Sudoi A., De Vries J. and Kamuya D, A scoping review of considerations and practices for benefit sharing in biobanking, $B M C$ Medical Ethics, 2021, Vol. 22, No. 102

[55] Rogers J. et al, Biobankonomics: A Taxonomy for evaluating the economic benefits of standardized centralized human biobanking for translational research, Journal of the National Cancer Institute Monographs, Vol. 42, 2011, pp. $32-38$

[56] Caenazzo L, Tozzo P, The Future of Biobanking: What is next?, BioTech, Vol. 9, No. 4, 2020, doi: 10.3390/biotech9040023

\section{Contribution of individual authors to the creation of a scientific article (ghostwriting policy)}

Conceptualization - L’ubica Kotorová Slušná, Miroslav Balog

Methodology - Vladimír Baláž, Martina Antošová, Lubica Kotorová Slušná

Writing - original draft preparation - L'ubica Kotorová Slušná, Vladimír Baláž, Miroslav Balog and Richard Filčák

Writing - review and editing - Edita Nemcová, Tomáš Jeck, Martina Antošová

Supervision - Vladimír Baláž, Miroslav Balog Funding acquisition - Miroslav Balog, Martina Antošová

\section{Sources of funding for research presented in a scientific article or scientific article itself}

This publication has been produced with the support of the Integrated Infrastructure Operational Program for the project: Systemic public research infrastructure - biobank for cancer and rare diseases, ITMS: 313011AFG5, co-financed by the European Regional Development Fund

\section{Creative Commons Attribution}

\section{License 4.0 (Attribution 4.0}

International , CC BY 4.0)

This article is published under the terms of the Creative Commons Attribution License 4.0 https://creativecommons.org/licenses/by/4.0/deed.en US 


\section{Appendix}

Figure 4 Correlation between total population and the total number of projects (Participant country in blue, Coordinator country in red)

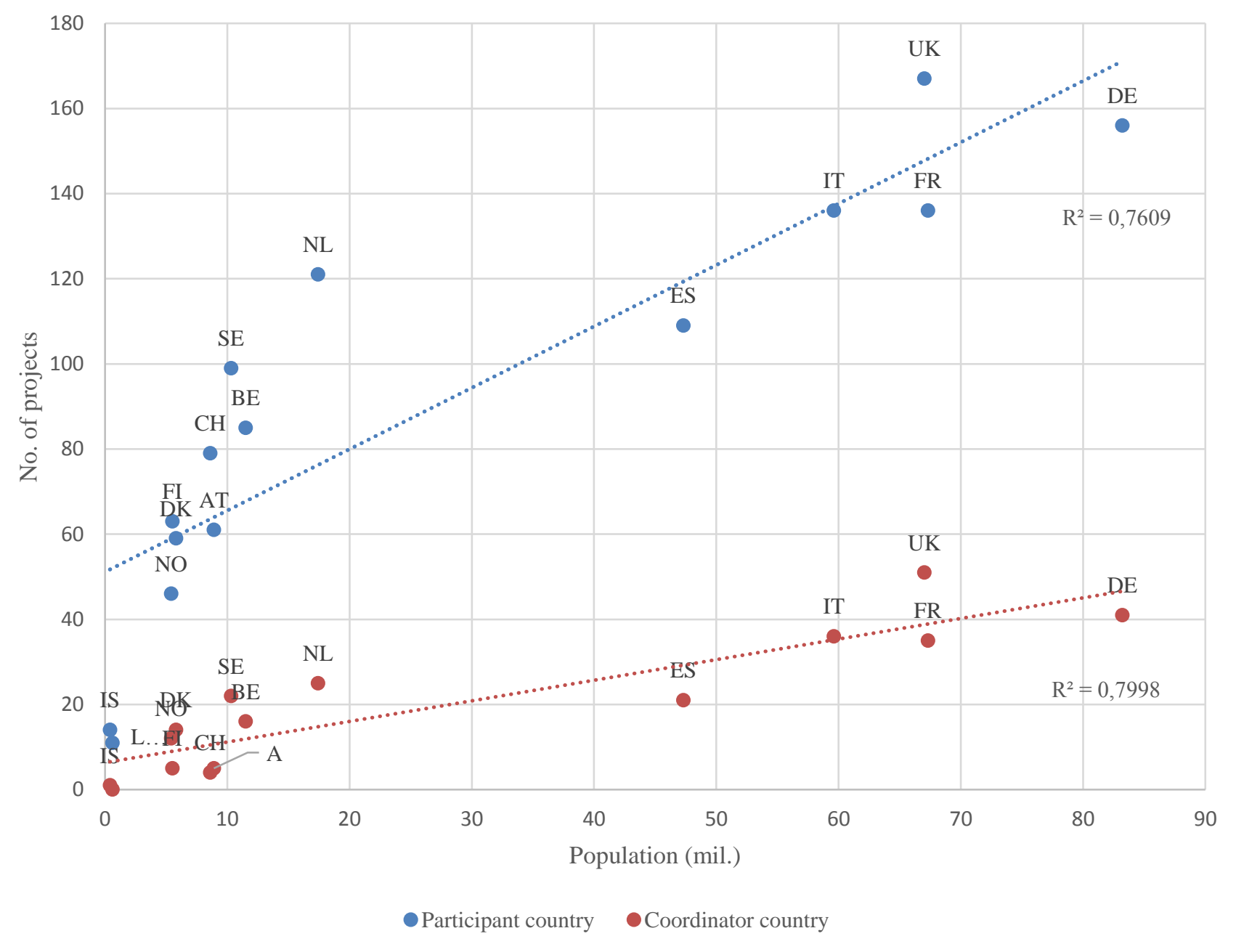


Fig. 7 Regional or global biobanking organisations, initiatives or projects according to the date of their creation

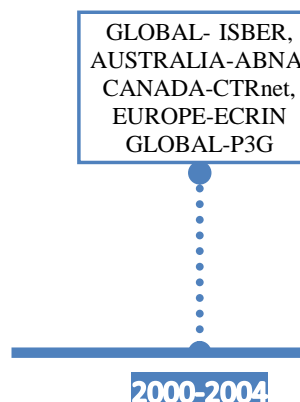

GLOBAL-The Marble Arch Working Group,

USA- Office of Biobanking and

Biospecimen Research,

ASIA- Asian Network of

Research Resource Centers

EUROPE-EPMA

$2000-2004$

Notes: International Society for Biological and Environmental Repositories (ISBER), Australian Biospecimen Network Association (ABNA), Canadian Tissue Repository Network (CTRnet), The European Clinical Research Infrastructure Network (ECRIN), Public Population Project in Genomics and Society (P3G), European Association for Predictive, Preventative and Personalized Medicne (EPMA), Global Alliance for Genomics and Health (GA4GH), The European, Middle Eastern \& African Society for Biopreservation \& Biobanking (ESBB ), National BioService (NBS), The Human Heredity and Health in Africa (H3 Africa), Bridging Biobanking and Biomedical Research across Europe and Africa (B3Africa), Low and middle income countries (LMIC) Biobank and cohort building network (BCNet) 